\title{
USO DE MOEDAS DE CENTAVOS DE REAL EM UMA DISCUSSÃO SOBRE DENSIDADE E EMPUXO
}

\author{
Thalita Ferreira Menegassi de Souza ${ }^{1}$ \\ Anderson O. Ribeiro
}

\begin{abstract}
RESUMO: Qual a importância da densidade em nosso cotidiano? E o empuxo? Muitos alunos já se fizeram estas e outras perguntas, principalmente quando estes conceitos são apresentados sem qualquer relação com a realidade cotidiana. Neste artigo apresentamos uma possibilidade de trabalho interdisciplinar com os temas acima a partir de um experimento simples que possibilita a medida da relação entre a massa e o volume de diferentes moedas do Real, dinheiro oficial do Brasil. A proposta aqui discutida foi realizada com um grupo de alunos de um curso preparatório popular da cidade de Ribeirão Preto SP, o CIMEAC - Conexão, e pode ser reproduzida por educadores em qualquer ambiente escolar do Brasil, sem a necessidade de uso de um laboratório de ciências. A partir da determinação da densidade do material, determinados pela análise gráfica dos dados obtidos, pode-se introduzir em sala de aula uma discussão sobre os conceitos teóricos e as aplicações práticas da Densidade e do Empuxo, mostrando ao aluno sua importância na produção e utilização de materiais e artefatos presentes em seu dia a dia.
\end{abstract}

Palavras-chave: Ensino de Ciências; Densidade; Empuxo.

ABSTRACT: This paper discusses the importance of density and the thrust in everyday life, by emphasizing an interdisciplinary approach in the teaching of sciences, dealing with a simple experiment which makes possible the measure of the relation between mass and volume of different Brazilian "Real" coins. The purpose we discuss here has already been done in a group of students in "CIMEAC-Conexão", a popular school in Ribeirão Preto - São Paulo.

Keywords: Teaching of Sciences; Density; Thrust.

\section{INTRODUÇÃO}

Por que uma bola de isopor "flutua" e uma bola de chumbo "afunda" quando colocados em um tanque cheio de água? Por que algumas bexigas quando cheias "flutuam" no ar e outras não? Estas questões podem encontrar respostas na análise de um conceito relativamente simples: a densidade. Neste caso, na densidade relativa entre o material e o meio em que este se encontra.

A densidade absoluta (ou massa específica) é uma característica própria de cada elemento, substância ou material [1], sendo definida como a razão entre a massa da amostra o volume ocupado por uma esta (1):

\footnotetext{
${ }_{1}^{1}$ Mestranda no Programa de Pós-Graduação de Ciência e Tecnologia/Química na Universidade Federal do ABC.

2 Professor adjunto do Centro de Ciências Naturais e Humanas da Universidade Federal do ABC, campus de Santo André. Doutorado em Química Inorgânica pela USP. Pós-Doutorado em Química Orgânica pela Universidade de Aveiro (Portugal).
} 


$$
d=\frac{m}{V},
$$

onde $\mathrm{m}$ é a massa (em gramas) e $\mathrm{V}$ é o volume $\left(\mathrm{em} \mathrm{cm}^{3}\right)$.

O valor da densidade é sempre o mesmo para qualquer quantidade do elemento, composto ou mistura analisada, sendo, portanto, classificada como uma propriedade intensiva. Como consequência primeira, a densidade pode ser utilizada para a identificação ou mesmo para a separação de materiais [2].

A decantação, por exemplo, quando empregada no tratamento de água, se baseia na diferença entre a densidade da água $\left(1,0 \mathrm{~g} . \mathrm{cm}^{-3}\right)$ e a dos flocos formados pela sujeira glomerada e ação de um agente químico coagulante, proporcionando o deposito deste no fundo dos tanques, facilitando sua retirada [3]. No simples ato de pescar com vara e anzol, a densidade também tem um papel importante, já que uma bóia (menos densa que a água) é posicionada na linha para determinar a profundidade que o pescador deseja que o anzol (mais denso que a água) atinja.

Por empregos como este, a densidade está popularmente relacionada com o conceito de "boiar" e "afundar". Mas será que podemos afirmar que um objeto com densidade maior que $1,0 \mathrm{~g} . \mathrm{cm}^{-3}$ (feito com ferro, por exemplo) irá sempre afundar se colocado na água? Sim? Então como um barco fabricado quase que completamente de ferro "flutua" sobre a água?

Um conceito muitas vezes desconhecido e que possui um papel importante nesta questão é o Empuxo. Quando um corpo é imerso em água irá deslocar uma determinada porção do líquido, já que dois corpos não ocupam o mesmo lugar no espaço. O Princípio de Arquimedes define que um corpo imerso parcial ou totalmente num líquido sofre a ação de uma força vertical orientada de baixo pra cima, denominada Empuxo, cuja intensidade é igual ao Peso (força Peso) do líquido deslocado mas na direção oposta [4].

Então, sobre um corpo imerso em um líquido, temos a atuação das seguintes forças: para baixo, em direção a centro da Terra, a força Peso (P), que é obtida pela multiplicação da massa do corpo pela gravidade $\left(P_{\text {corpo }}=m_{\text {corpo.g }}\right)$ e; para cima, 0 Empuxo (E), uma força vertical contrária, que é igual a força Peso da massa da quantidade de água deslocada pelo corpo imerso na água $\left(E=P_{\text {água }}=m_{\text {água.g }}\right.$ [5-6].

Um esquema das forças presentes sobre um corpo em equilíbrio quando imerso em água pode ser verificado abaixo: 


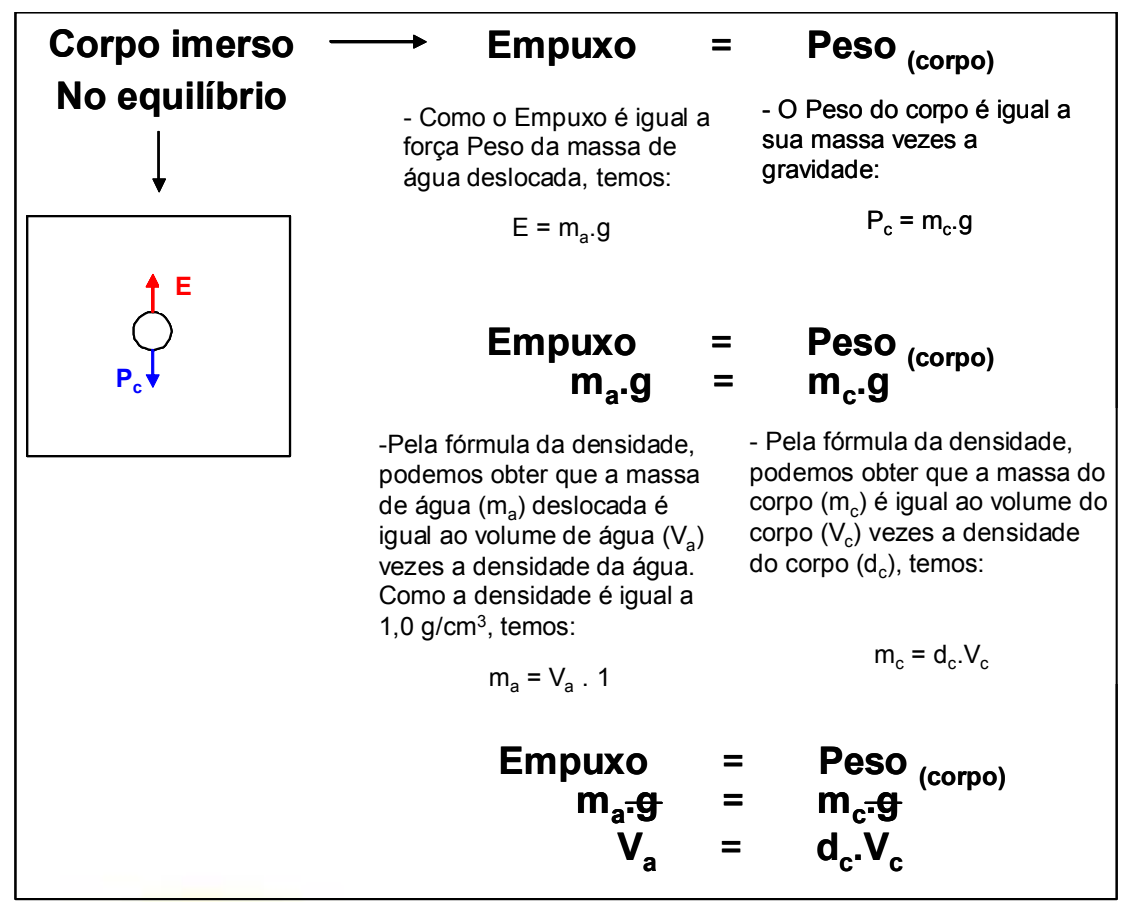

Esquema 01. Forças atuando em um corpo em equilíbrio em água.

De acordo com o esquema apresentado, temos as possíveis situações:

1) Quando um corpo está completamente submerso em água, o volume deslocado de água $\left(V_{a}\right)$ é exatamente igual ao volume do corpo $\left(V_{c}\right)$. Assim, se a densidade do corpo $\left(d_{c}\right)$ for maior que $1,0 \mathrm{~g} / \mathrm{cm}^{3}$, o valor da força Peso $\left(P_{c}\right)$ será maior que o empuxo $(E)$, e o material "afundará".

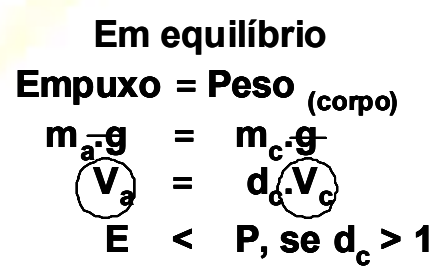

Se a densidade do corpo $\left(d_{c}\right)$ for menor do que $1,0 \mathrm{~g} \mathrm{~cm}^{-3}$, o corpo voltará a superfície e flutuará. Se for exatamente igual a $1,0 \mathrm{~g} . \mathrm{cm}^{-3}$, o corpo ficará em equilíbrio com a água (nem afunda nem flutua).

2) Quando um corpo está parcialmente submerso em água ("flutuando"), a força Empuxo exercida no corpo precisa ser igual a força Peso $\left(P_{c}\right)$ para que o sistema permaneça em equilíbrio. Assim, o valor da multiplicação do volume do corpo pela sua densidade $\left(d_{c} . V_{c}\right)$ deve ser igual ao volume de água deslocado $(E=$ $\left.V_{a}\right)$. 
Se um corpo "flutua" em água, seu volume total $\left(\mathrm{V}_{\mathrm{c}}\right)$ é maior que o volume de água deslocado $\left(\mathrm{V}_{\mathrm{a}}\right)$. Portanto, para que um material "flutue" em água é necessário que sua densidade $\left(d_{c}\right)$ seja menor que $1,0 \mathrm{~g} / \mathrm{cm}^{3}$, já que o cálculo de $\left(d_{c} . V_{c}\right)$ precisa dar um valor igual ao volume de água deslocado $\left(V_{a}\right)$, que como vimos é menor.

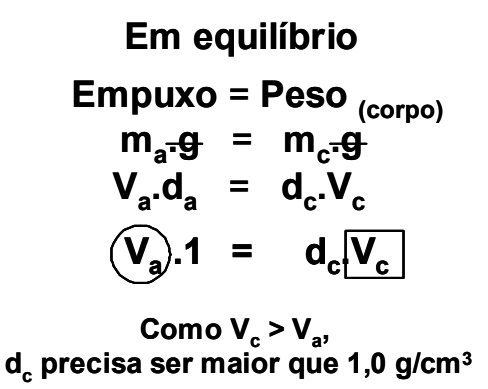

É de se esperar, portanto, que materiais com densidade menor que $1,0 \mathrm{~g} . \mathrm{cm}^{-3}$ desloquem um pequeno volume de água, ficando emersos ("flutuam"). Outra possibilidade para que um material flutue em água, mesmo que sua densidade seja maior que 1,0 g. $\mathrm{cm}^{-3}$, é fazer com que o volume de água deslocado $\left(\mathrm{V}_{\mathrm{a}}\right)$ seja grande. Neste caso, o valor da multiplicação da densidade do corpo pelo seu volume $\left(d_{c} \cdot V_{c}\right)$ pode ser igual ao grande volume de água deslocado $\left(\mathrm{V}_{\mathrm{a}}\right) \mathrm{e}$, mesmo que a densidade do material seja maior que a da água, ele irá "flutuar".

Agora podemos explicar melhor a questão levantada sobre os navios, que conseguem permanecer emersos mesmo sendo construídos com um material mais denso que a água (Ferro). Para navegar sobre a água, os navios são construídos de modo a combinar os dois meios possíveis para flutuar discutidos acima: uma menor densidade e um grande deslocamento de volume de água.

Os navios possuem partes ocas ou menos densas em seu interior, o que ameniza o peso da embarcação. Além disso, o modo como são construídos permite que eles desloquem uma grande quantidade de água, aumentando a força Empuxo exercida sobre o navio [7].

Pode-se compreender também, de acordo com as forças em questão, porque os barcos podem naufragar. A entrada de água em uma embarcação faz com que o volume de água deslocado pelo barco diminua, o que diminui, conseqüentemente, o Empuxo exercido sobre ele [8-9]. O desequilíbrio entre as forças faz o navio afundar cada vez mais. A medida que mais água entra, menos favorecido fica o Empuxo, o que leva a submersão completa da embarcação.

Assim como o Empuxo é essencial para o perfil das construções navais, a densidade é uma característica importante para definir a aplicação de materiais 
produzidos pela indústria. O PVC, por exemplo, é utilizado em tubulações por ser um polímero resistente, de fácil produção e fácil moldagem. Além disso, por possuir densidade maior que $1,0 \mathrm{~g} \cdot \mathrm{cm}^{-3}$, pode ser utilizado em sistemas de captação em tanques, lagos ou rios sem a necessidade de uma grande força para mantê-lo submerso na água [10].

Neste artigo apresentamos um experimento que pode ser utilizado por educadores em qualquer escola ou curso preparatório popular do Brasil para a discussão sobre os conceitos de densidade e Empuxo. Medindo o volume de moedas de centavos de Real, com um aparato construído com materiais bastante acessíveis, demonstramos a possibilidade de obtenção do valor da densidade do material com que as moedas são forjadas, o aço inoxidável.

Atualmente as moedas são feitas de aço inoxidável, devido à alta resistência a corrosão, resistência à oxidação, facilidade de conformação, resistência a altas temperaturas, além de uma relação favorável no custo/benefício deste material. Devido a essas características, o aço inoxidável é também empregado em construções, móveis, e componentes de equipamentos industriais [11].

Dado a estrutura inoxidável e resistente a deformação, a massa das moedas pouco se altera com o uso diário, mesmo após anos. Podemos então usar um valor padrão para sua massa, empregado no seu fabrico, e que ser obtido facilmente no site oficial da casa da moeda do Brasil [12].

Precisamos agora encontrar o outro valor necessário para o cálculo da densidade, o volume das moedas. Podemos determinar seu volume empregando o deslocamento do líquido obtido quando as moedas são submersas em água. 0 princípio do Empuxo demonstra que o volume deslocado por objetos submersos em determinado líquido é igual ao volume do próprio objeto. Conta à história que foi justamente determinando a pureza de moedas, na época feitas com ouro, que Arquimedes definiu o princípio do Empuxo [13].

Assim, o procedimento que propomos neste artigo para a determinação da densidade das moedas é o emprego de um gráfico originado pela massa versus o volume obtido com a submersão de uma série de moedas de aço em um recipiente graduado cheio de água. 


\section{OBJETIVOS}

Determinar a densidade do aço inoxidável, que é empregado na fabricação de moedas de Real e, a partir dos resultados, discutir alguns conceitos como a densidade, o Empuxo e os gráficos da função do $1^{\circ} \mathrm{grau}$.

\section{PARTE EXPERIMENTAL}

Para a comparação do erro entre o valor exato da densidade das moedas e o valor obtido no experimento proposto por nós, foram determinadas as massas das moedas ( $R \$ 0,10, R \$ 0,25$ e $R \$ 0,50$, todas da família original) com a utilização de balança analítica e seus respectivos volumes com uma proveta graduada (volume).

1 - OBTENÇÃO DA DENSIDADE DAS MOEDAS: PROCEDIMENTO COM INSTRUMENTOS ANALÍTICOS

Este procedimento foi realizado com equipamentos dos laboratórios didáticos da Universidade Federal do ABC [14].

1.1 - Determinação da massa média das moedas e do desvio padrão.

Pesou-se individualmente, em uma balança analítica, cinqüenta moedas de $\mathrm{R} \$ 0,10, \mathrm{R} \$ 0,25$ e $\mathrm{R} \$ 0,50$ da família original de moedas do Real, confeccionadas em aço inoxidável. Foi obtido o valor da média da massa e o desvio padrão para cada valor.

1.2 - Determinação do volume deslocado por uma série de moedas.

Em uma proveta graduada $(25,0 \mathrm{~mL})$, foi adicionado água até o volume de 5,0 $\mathrm{mL}$, o qual iremos chamar de volume inicial. A esta proveta adicionou-se uma moeda de um dos valores estudados (com sua massa previamente obtida na balança analítica) e anotou-se o volume de água deslocado. Em seguida, colocou-se outra moeda de mesmo valor (também com a massa previamente obtida), juntamente com a anterior, e anotou-se o volume deslocado em relação ao volume inicial. Este passo foi seguido para um número de dez moedas, sempre com adições consecutivas. Foi 
elaborada uma tabela com a massa total em cada medida e o respectivo volume total de água deslocado.

Este procedimento, de medição do volume deslocado por uma série de moedas ao invés da medida do volume de cada moeda individualmente, diminui o erro das medidas, aproximando a determinação da densidade do seu valor real.

\section{3 - Construindo o gráfico}

Para a determinação da densidade, foi elaborado um gráfico obtido pelos dados da massa total de moedas em cada medida (eixo ordenadas) versus o volume total de água deslocado por estas (abscissas).

\section{2 - OBTENÇÃO DA DENSIDADE DAS MOEDAS: PROCEDIMENTO} PROPOSTO COM ARTEFATO CONSTRUÍDOS COM MATERIAIS ACESSÍVEIS

Os resultados aqui apresentados foram obtidos durante o trabalho com um grupo de alunos de um curso preparatório popular da cidade de Ribeirão Preto - SP, o CIMEAC - Conexão.

Materiais empregados:

- 50 moedas de aço inoxidável (família original do real).

- bebedouro de plástico transparente para pássaros, com abertura suficiente para entrada de moedas.

- caneta para marcar plástico.

- seringa de plástico com graduação de 0,5 em 0,5 mL.

- régua, transferidor e papel milimetrado.

\section{Procedimentos:}

\section{1 - Construindo a proveta}

Primeiramente, a boca do bebedouro de pássaros foi retirada. Virando-o de cabeça para baixo, é possível adicionar água e também imergir uma série de moedas. Para a elaboração da graduação, despejou-se, com o auxílio da seringa, $1,0 \mathrm{~mL}$ de água no bebedouro, marcando a altura obtida com uma caneta. Este procedimento foi repetido com adições sucessivas de $0,5 \mathrm{~mL}$ de água, até o volume 
final de 15,0 mL. Assim, o bebedouro ficou parecido com uma "proveta de laboratório" (Figura 1).
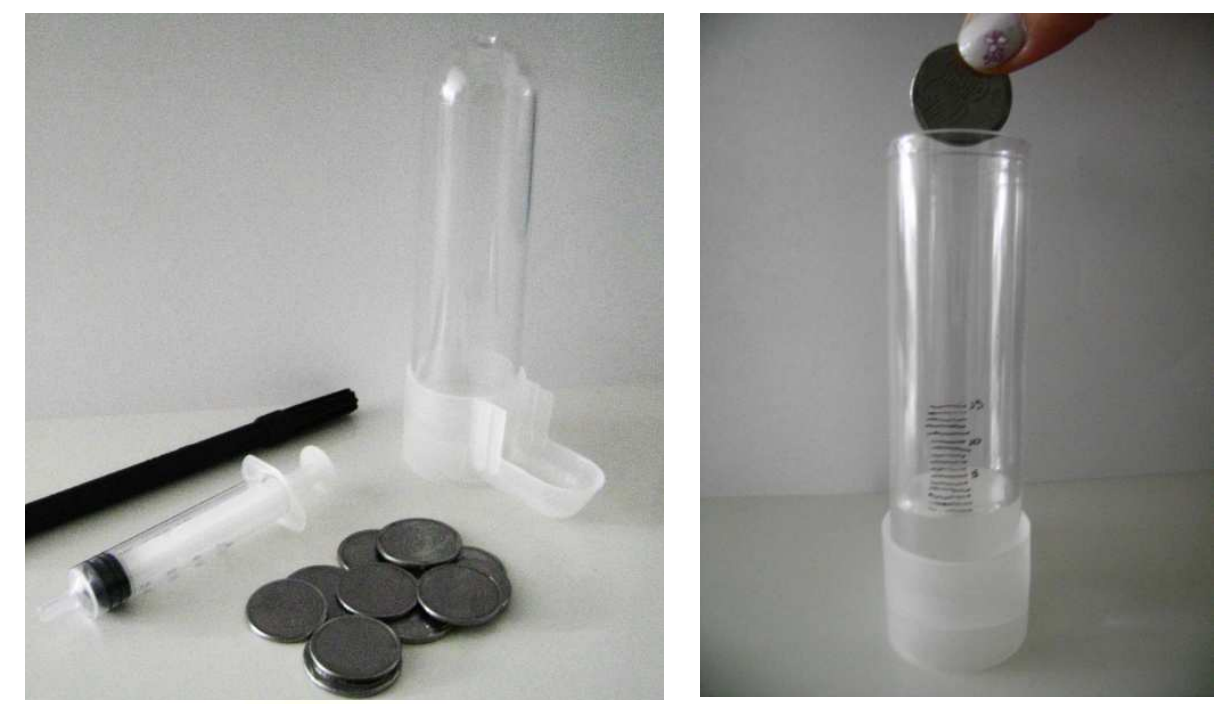

Figura 1: Artefato proposto para a medida de volume das moedas

2.2 - Determinação do volume associado à massa de uma seqüência de moedas

Na proveta construída, foi adicionada água até o volume de 3,0 $\mathrm{mL}$ até atingir a marca previamente definida para este volume. Iremos considerar este valor como o volume inicial. A esta "proveta" adicionou-se uma moeda de um dos valores estudados e anotou-se o volume de água deslocado. Em seguida, colocou-se outra moeda de mesmo valor, juntamente com a anterior, e anotou-se o volume deslocado em relação ao volume inicial. Este passo foi seguido para dez moedas, sempre com adições consecutivas. Foi elaborada uma tabela com a massa total em cada medida (utilizando-se para cada moeda o valor da massa média) e o respectivo volume total de água deslocado.

\section{3 - Construindo o gráfico}

O gráfico para a determinação da densidade foi construído, em papel milimetrado, com as ordenadas (eixo y) dadas pela soma das massas das moedas e as abscissas dadas pelo respectivo volume total deslocado (eixo $\mathrm{x}$ ). Por meio da medida do ângulo de inclinação do gráfico $(\alpha)$, obtido com o auxílio do transferidor, é possível encontrar a densidade da moeda, pela relação: $d=\operatorname{tg} \alpha=\Delta x / \Delta y[15-17]$. 


\section{RESULTADOS E DISCUSSÃO}

A tabela 1 apresenta as massas médias obtidas para um conjunto de 100 (cem) moedas usadas no dia a dia e pesadas na balança analítica, bem como o valor oficial de produção fornecido pela casa da moeda.

Tabela 1: Massa das moedas.

\begin{tabular}{|c|c|c|}
\hline Valores (em R\$) & Massa média (g) & Massa (g; valores oficiais) \\
\hline 0,10 & 3,64 & 3,59 \\
\hline 0,25 & 4,78 & 4,78 \\
\hline 0,50 & 3,94 & 3,92 \\
\hline
\end{tabular}

Verificou-se que as massas das moedas de um mesmo valor não apresentam variação significativa entre si, nem mesmo uma diferença significativa com o valor padrão de fabricação fornecido pelo órgão responsável pela sua manufatura.

Assim, para a realização do experimento em sala de aula com a utilização da massa média apresentada aqui, ou do valor padrão de fabricação, o erro propagado no cálculo da densidade será pequeno.

No procedimento realizado com balança analítica e proveta de vidro, encontrou-se os seguintes valores de densidade: $7,57 \mathrm{~g} . \mathrm{cm}^{-3}, 7,83 \mathrm{~g} . \mathrm{cm}^{-3}$ e 7,72 g. $\mathrm{cm}^{-3}$, respectivamente, para as moedas de $\mathrm{R} \$ 0,10, \mathrm{R} \$ 0,25$ e $\mathrm{R} \$ 0,50$. A média da densidade entre as três medidas realizadas foi de $7,63 \mathrm{~g} \cdot \mathrm{cm}^{-3}$. Este valor é bastante próximo do valor da densidade média do aço, que é $7,86 \mathrm{~g} . \mathrm{cm}^{-3}$.

O gráfico 1 abaixo apresenta o resultado das medidas realizadas para a moeda de $\mathrm{R} \$ 0,25$ com o artefato de plástico aqui proposto durante os trabalhos com alunos do CIMEAC - Conexão. A massa considerada para cada moeda foi de 4,78 gramas. O gráfico apresentado foi obtido em computador.

\begin{tabular}{|cc|}
\hline Volume deslocado $(\mathrm{ml})$ & Massa total $(\mathrm{g})$ \\
1,0 & 4,78 \\
2,0 & 9,56 \\
2,5 & 14,34
\end{tabular}




\begin{tabular}{|ll|}
3,3 & 19,12 \\
4,0 & 23,90 \\
4,5 & 28,68 \\
5,2 & 33,46 \\
6,0 & 38,24 \\
6,5 & 43,02 \\
7,0 & 47,80 \\
8,2 & 52,58 \\
8,5 & 57,36 \\
9,0 & 62,14 \\
\hline
\end{tabular}

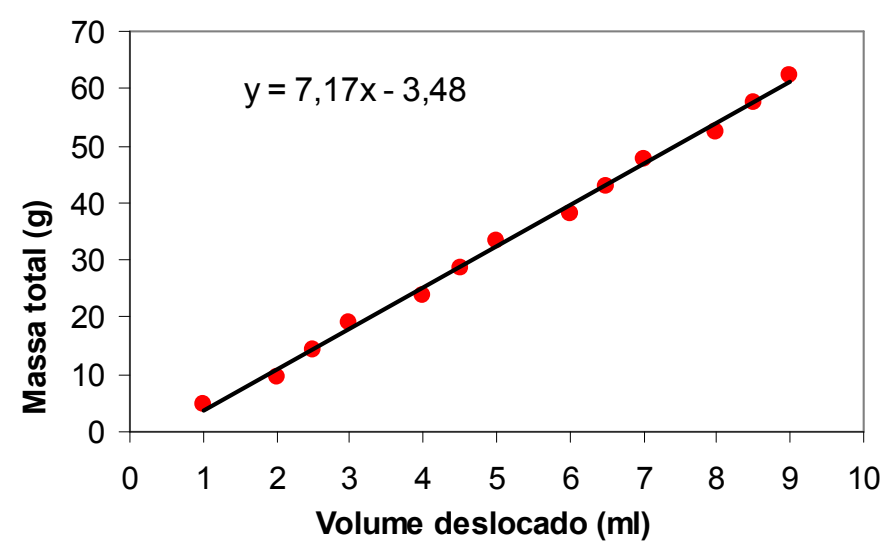

Gráfico 1: Resultado obtido para as moedas de $\mathrm{R} \$ 0,25$ medindo o volume com o artefato de plático proposto.

O valor da densidade encontrado para a moeda de $\mathrm{R} \$ 0,25$ empregando o artefato construído foi de $7,17 \mathrm{~g} . \mathrm{cm}^{-3}$. Apesar do valor apresentar um erro de $8,7 \%$ em relação ao valor teórico da densidade do aço, podemos considerar um resultado bastante bom em vista do instrumento de medida utilizado.

Para as moedas de $R \$ 0,10$ e $R \$ 0,50$, os valores encontrados foram 7,56 g. $\mathrm{cm}^{-3}$ e $7,88 \mathrm{~g} \cdot \mathrm{cm}^{-3}$, respectivamente. Considerando-se as três medições, a média encontrada para a densidade é de $7,53 \mathrm{~g} . \mathrm{cm}^{-3}$, valor bem próximo ao obtido no experimento com instrumentos de precisão e do valor teórico do aço.

Os resultados encontrados mostram que o artefato aqui proposto pode ser utilizado pelos educadores em qualquer ambiente escolar sem comprometer a interpretação dos conceitos por parte dos alunos. Pelo contrário, a realização das medições em sala de aula pode proporcionar uma melhoria na interpretação e contextualização dos conceitos abrangidos, mostrando-se, portanto, importante paro o processo de ensino aprendizagem destes temas.

Ainda, propomos que os educadores utilizem folhas milimétricas para a confecção dos gráficos, e de um transferidor para a obtenção da tangente do ângulo de inclinação no trabalho de obtenção do valor da densidade das moedas. Esta atividade pode propiciar uma discussão sobre conteúdos relacionados com funções matemáticas e de outros conteúdos relacionados a análises gráficas.

Também, outros temas relacionados podem ser abordados antes e depois de realizar a atividade proposta. Na Figura 2, apresentamos um mapa com alguns temas relacionados que foram discutidos ao longos dos trabalhos apresentados neste texto. Esta é apenas uma possibilidade, já que no decorrer das atividades 
novas relações e interpretações podem ser discutidas de acordo com os dados obtidos.

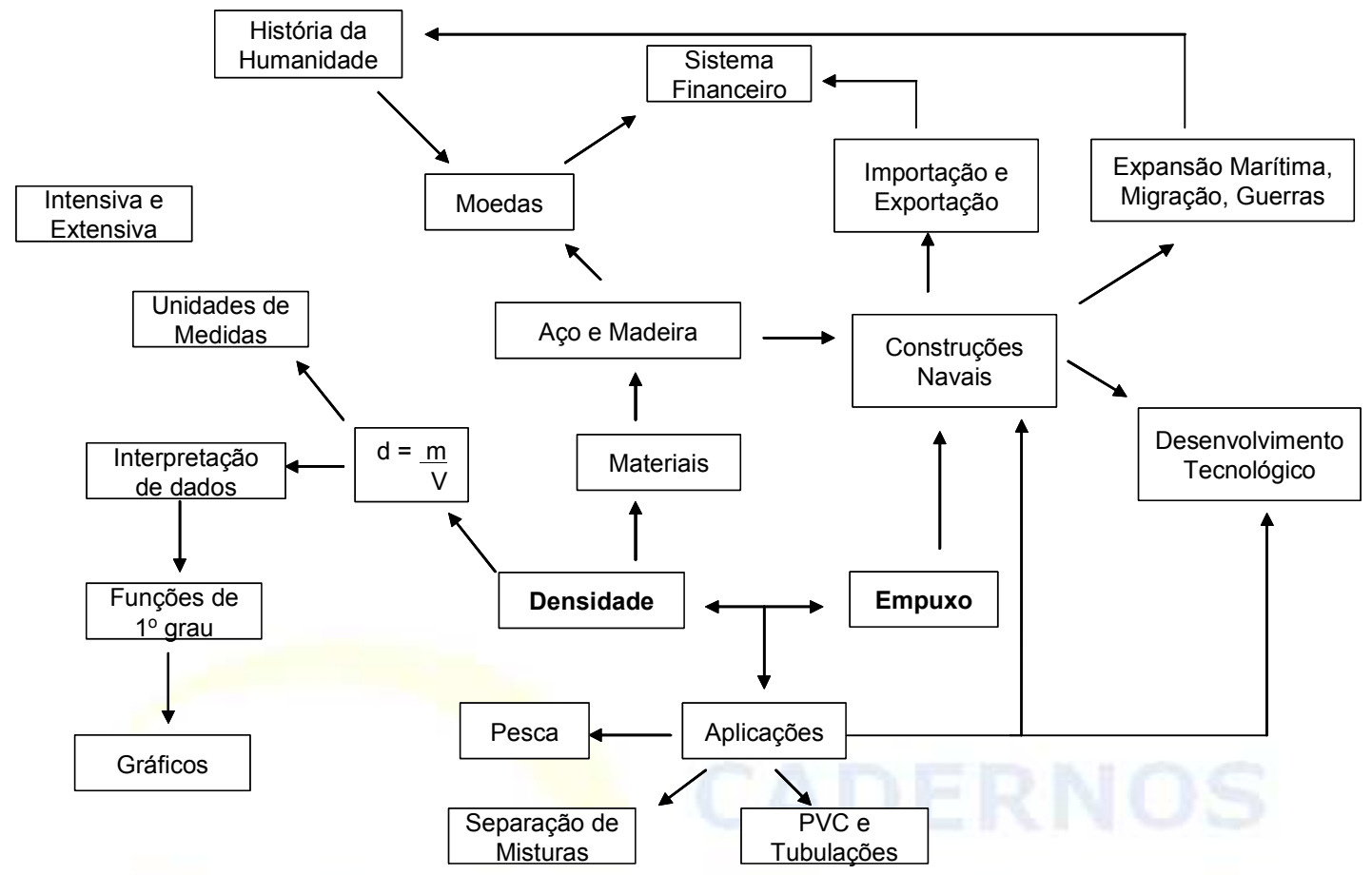

Figura 02: Conceitos relacionados ao tema abordado.

\section{CONCLUSÃO}

Os resultados obtidos evidenciam que o valor da densidade obtido com 0 procedimento proposto apresenta uma grande proximidade ao valor teórico, o que mostra que o artefato construído pode ser empregado em qualquer ambiente de ensino sem grandes prejuízos para interpretação dos temas. Com esta proposta, os educadores poderão realizar um experimento bastante simples e interessante, e em um ambiente que não necessariamente um laboratório de ciência.

\section{SITES ACESSADOS}

http://www.casadamoeda.gov.br - Acesso em dezembro de 2012. http://www.ufabc.edu.br 


\section{REFERÊNCIAS BIBLIOGRÁFICAS}

ANTON, Howard. Cálculo, um novo horizonte. 6. ed. Porto Alegre: Bookman, 2000.

ATKINS, Peter; JONES, Loretta. Princípios de Química: questionando a vida moderna e o Meio Ambiente. 3. ed. Porto Alegre: Bookman, 2006.

BONJORNO, Regina; BONJORNO, José Roberto; BONJORNO, Valter; RAMOS, Clinton Marcico. Física Completa: volume único. 2. ed. São Paulo: FTD, 2001.

CALLISTER JR, William. Ciência e engenharia de materiais: uma introdução. 5. ed. Rio de Janeiro: LTC, 2002.

COTRIM, Gilberto. História para o ensino médio: Brasil e geral. Volume único. 1. ed. São Paulo: Saraiva, 2002.

FELTRE, Ricardo. Fundamentos da Química. 1. ed. São Paulo: Moderna, 1990.

FERRARO, Nicolau Gilberto; SOARES, Paulo Antônio de Toledo. Física Básica $2^{\circ}$ grau. São Paulo: Atual, 1981.

FINNEY, Ross. Cálculo: volume 1. 10. ed. São Paulo: Pearson Addisson Wesley, 2002.

HALLIDAY, David; RESNICK, Robert; WALKER, Jearl. Fundamentos de Física: volume 2. 7. ed. Rio de Janeiro: LTC, 2006.

HINRICHS, Roger; KLEINBACH, Merlin. Energia e Meio Ambiente. 3. ed. São Paulo: Pioneira Thonson Learning, 2003.

SAFIER, Fred. Teoria e problemas de pré-cálculo. Porto Alegre: Bookman, 2003.

TIPLER, Paul Allan. Física para cientistas e engenheiros: volume 1- Mecânica, oscilações, ondas e termodinâmica. 5. ed. Rio de Janeiro: LTC, 2006.

USBERCO, João; SALVADOR, Edgar. Química Essencial. 1. ed. São Paulo: Saraiva, 2001.

VAN VLACK, Lawrence. Princípios de Ciência dos materiais. São Paulo: Blücher, 1970.

Campus, 1984.

Princípios de Ciência e Tecnologia dos Materiais. Rio de Janeiro: 